\title{
Optimization of Bleaching Process of Crude Palm Oil by Activated Plantain (Musa paradisiaca) Peel Ash Using Response Surface Methodology
}

\author{
Wuraola Abake Raji*, Rowland Ugochukwu Azike, Fredericks Wirsiy Ngubi \\ Department of Chemical Engineering, Igbinedion University, Okada, Nigeria \\ Email: *raji.wuraola@iuokada.edu.ng
}

How to cite this paper: Raji, W.A., Azike, R.U. and Ngubi, F.W. (2019) Optimization of Bleaching Process of Crude Palm Oil by Activated Plantain (Musa paradisiaca) Peel Ash Using Response Surface Methodology. Open Journal of Optimization, 8, 38-46. https://doi.org/10.4236/ojop.2019.81004

Received: February 1, 2019

Accepted: March 16, 2019

Published: March 19, 2019

Copyright $\odot 2019$ by author(s) and Scientific Research Publishing Inc. This work is licensed under the Creative Commons Attribution International License (CC BY 4.0).

http://creativecommons.org/licenses/by/4.0/

\begin{abstract}
The bleaching of crude palm oil using activated plantain peel ash (APPA) was studied in this work. Historical data design (HDD) in response surface methodology (RSM) experimental design was employed to optimize and correlate the process operating parameters (temperature, time and adsorbent dosage) to the percentage bleaching efficiency. The analysis of the results showed that the quadratic effects of the operating parameters were significant. The optimum condition for the maximum adsorption efficiency of $70.04 \%$ was obtained at $160^{\circ} \mathrm{C}$ temperature, 60 minutes reaction time, and $4 \mathrm{~g}$ adsorbent dosage. The predicted bleaching efficiency of $74 \%$ was in good agreement with the optimum experimental yield. This study has revealed that APPA is a good source of adsorbent for palm oil bleaching.
\end{abstract}

\section{Keywords}

Bleaching, Activated Plantain Peel Ash, Adsorption, Bleaching Efficiency, Response Surface Methodology

\section{Introduction}

Palm oil is an edible vegetable oil, produced by extracting its oil from the fresh fleshy fruits of oil palms which serves as an important ingredient for the food industry because of its superior characteristics and attributes [1]. Palm oil in its raw form contains impurities such as organic pigments, oxidation metals, trace metals and trace soaps [2]. For palm oil to be edible these impurities which negatively influence the taste and smell of the oil as well as its appearance and 
shelf life stability must be removed through the bleaching process. The bleaching of the oil is accomplished via adsorption of the impurities onto a surface-active micro porous adsorbent material or bleaching agent for a period of time by Vander Waal forces [3] [4].

The refining of palm oil through adsorptive bleaching remains inevitable in the palm oil refining industry. The major adsorbent used in the industry is bleaching earth, but it is expensive in terms of production cost. To avert this, utilization of agro-wastes as adsorbents is currently receiving wide attention because of their abundant availability and low cost owing to relatively high fixed carbons and presence of porous structures [5]. Unripe plantain peel is a carbonaceous waste material that is currently disposed of either by burning in the open or left in the field to decay. Both disposal methods contribute to environmental degradation [6]. Bleaching of palm oils with activated unripe plantain peel ash (APPA) therefore merits more investigations in order to combat environmental pollution and to reduce cost of production in the refining industry.

Optimization of the crude palm oil process variables is viable through the application of statistical experimental design techniques in adsorption process development that results in improved product yields and reduced development time and overall costs [7]. Regular methods of studying a process by maintaining other parameters involved at an undesignated constant level do not describe the combined effect of all the parameters involved [8]. This is referred as one factor at a time. This method is time consuming and requires a large number of experiments to determine optimum levels, which are unreliable [3]. These limitations can be avoided by optimizing all the parameters collectively by statistical experimental design such as response surface methodology [9].

Response surface methodology (RSM) is based on polynomial surface analysis and it is a collection of mathematical and statistical techniques that are useful for the modelling and analysis of problems in which a response of interest is influenced by several variables [10]. It also employs multiple regression and correlation analyses as tools to assess the effects of two or more independent factors on the dependent variables [11]. RSM has been applied in researches into complex variable processes by many authors to optimize operational conditions of processes [3] [8] [12] [13] [14] [15]. In this study, RSM was used to optimize the bleaching process variables such as temperature, contact time and adsorbent dosage in order to obtain optimum conditions for the bleaching of palm oil using Historical Data Design (HDD).

\section{Materials and Method}

The unripe plantain peels and crude palm olein (CPO) used in this study were obtained from the open market, Benin City, Edo State, Nigeria. The analytical grade reagents used was procured from LUCO-Consult Limited, Benin City. A constant gram of $\mathrm{CPO}$ was bleached with varying dosage of APPA at different temperatures and time. The heated mixture of $\mathrm{CPO}$ and APPA formed a slurry. 
The slurry was cooled at room temperature in a water bath and filtered with Whatman's filter paper for effective separation of the bleached oil and spent adsorbent. The Labscience 721A UV-Spectrophotometer was used to analyse the bleached oil. The percentage bleached oil was determined using Equation (1) [3].

$$
\% \text { Bleachedoil }=\frac{A_{0}-A}{A_{0}} \times 100
$$

where $A_{0}$ is the absorbance of unbleached palm oil and $A$ is the absorbance of bleached palm oil.

\section{Experimental Design and Optimization}

The experimental design and statistical analysis were performed according to the response surface analysis method using Design Expert 7.0.0 (Stat-Ease Inc., Minneapolis, MN, USA) trial version software. Historical data design (HDD) was used for the optimization of bleached palm oil in order to examine the combined effect of the three different factors (independent variables): bleaching temperature, bleaching time and adsorbent dosage on bleaching performance (dependent variable). The statistical analysis was performed using: Analysis of Variance (ANOVA), regression analysis and response surface plots of the interaction effects of the factors to evaluate optimum conditions for the bleaching process. The effects of the process variables on the bleaching efficiency were calculated and their respective significant evaluated by ANOVA test. The p-value was used as the yardstick for measuring the significance of the regression coefficients, values of $\mathrm{p}$ greater than 0.05 signified that the coefficient is significant. The experimental data were fitted to the second-order polynomial regression model and the adequacy of the model tested by the coefficient of determination $R$-Squared $\left(R^{2}\right)$ value as compared to the adjusted R-Squared $\left(R^{2}\right)$ value.

\section{Results and Discussion}

\subsection{Regression Model Equation}

The developed model correlated the response to the process variables using second degree polynomial. The model selected was based on the highest order model where the additional terms were significant and the model was not aliased and there was reasonable agreement between Adjusted R-Squared and predicted R-squared (within 0.2 of each other). The predictive model was given in Equation (2) in a coded term. The coded equation is useful for identifying the relative significance of the factors by comparing factor coefficients. Base on the experimental design and the experimental results obtained, the second order response functions representing $\mathrm{Y}$ is the response for bleaching performance, $\mathrm{A}$ is the coded value of variable temperature $\left({ }^{\circ} \mathrm{C}\right), \mathrm{B}$ is the coded value of variable adsorbent dosage (gram) and $\mathrm{C}$ is the coded value of variable contact time (mins). From the model equation, time had highest effect on the bleaching performance with coefficient of 37.95 followed by temperature and lastly, adsorbent dosage. 


$$
\begin{aligned}
Y= & +49.29+16.34 * A+8.44 * B+37.95 * C+2.29 * A B+13.25 * A C \\
& -3.15 * B C-88.39 * A 2-1.71 * B 2+3.72 * C 2
\end{aligned}
$$

\subsection{Analysis of Variance (ANOVA)}

Table 1 shows the result of analysis of variance in which the Model F-value of 42.87 implies the model is significant. There is only a $0.01 \%$ chance that a "Model F-Value" this large could occur due to noise. Values of "Prob > F" less than 0.0500 indicate model terms are significant. In this case $\mathrm{A}, \mathrm{B}, \mathrm{C}, \mathrm{AC}, \mathrm{BC}$, $\mathrm{A} 2, \mathrm{~A} 2 \mathrm{C}$ are significant model terms. Values greater than 0.1000 indicate the model terms are not significant. In addition, the model did not show lack of fit and presented high determination coefficients, $\mathrm{R}^{2}=0.94871$ indicating that $94.8 \%$ of the variability was explained by the model shown in Table 2 . The "Pred R-Squared" of 0.8852 is in reasonable agreement with the "Adj R-Squared" of 0.9266. "Adeq Precision" measures the signal to noise ratio. A ratio greater than 4 is desirable. Your ratio of 22.636 indicates an adequate signal. This model can be used to navigate the design space.

\subsection{Model Diagnostic Plots}

\subsubsection{Normal Plot of Residuals}

Figure 1 depicts normal probability plot which indicates normal distribution of residuals, in which the points follows a straight line. Some moderate scatter points maybe expected even with normal data. Transformation of the response maybe needed to provide a better analysis if patterns look like an "S-shaped" curve.

Table 1. The analysis of variance (ANOVA) result.

\begin{tabular}{ccccccc}
\hline \multirow{2}{*}{ Source } & Sum of & S & & F & p-value & \\
& Squares & df & Mean & value & Prob $>$ F & \\
\cline { 5 - 7 } Model & $31,701.11$ & 19 & 1668.48 & 42.87 & $<0.0001$ & Significant \\
A-temp. & 530.15 & 1 & 530.15 & 13.62 & $<0.0006$ & \\
B-adsorbent & 164.21 & 1 & 164.21 & 4.22 & $<0.0459$ \\
C-time & 3317.94 & 1 & 3317.94 & 85.24 & $<0.0001$ \\
AB & 25.92 & 1 & 25.92 & 0.67 & $<0.4189$ \\
AC & 867.56 & 1 & 867.56 & 22.29 & $<0.0001$ \\
BC & 163.07 & 1 & 163.07 & 4.19 & $<0.0467$ \\
A^2 & 5208.88 & 1 & 5208.88 & 133.82 & $<0.0001$ \\
A^2C & 1245.62 & 1 & 1245.62 & 32.00 & $<0.0001$ \\
C^2 & 146.11 & 1 & 146.11 & 3.75 & $<0.0591$ \\
Residual & 1712.64 & 44 & 38.92 & & \\
Cor total & $33,413.75$ & 63 & & & \\
\hline
\end{tabular}


Table 2. Model summary statistics.

\begin{tabular}{cc}
\hline R-Squared & 0.9487 \\
\hline Adj R-Squared & 0.9266 \\
Pred R-Squared & 0.8852 \\
Adeq Precision & 22.636 \\
\hline
\end{tabular}
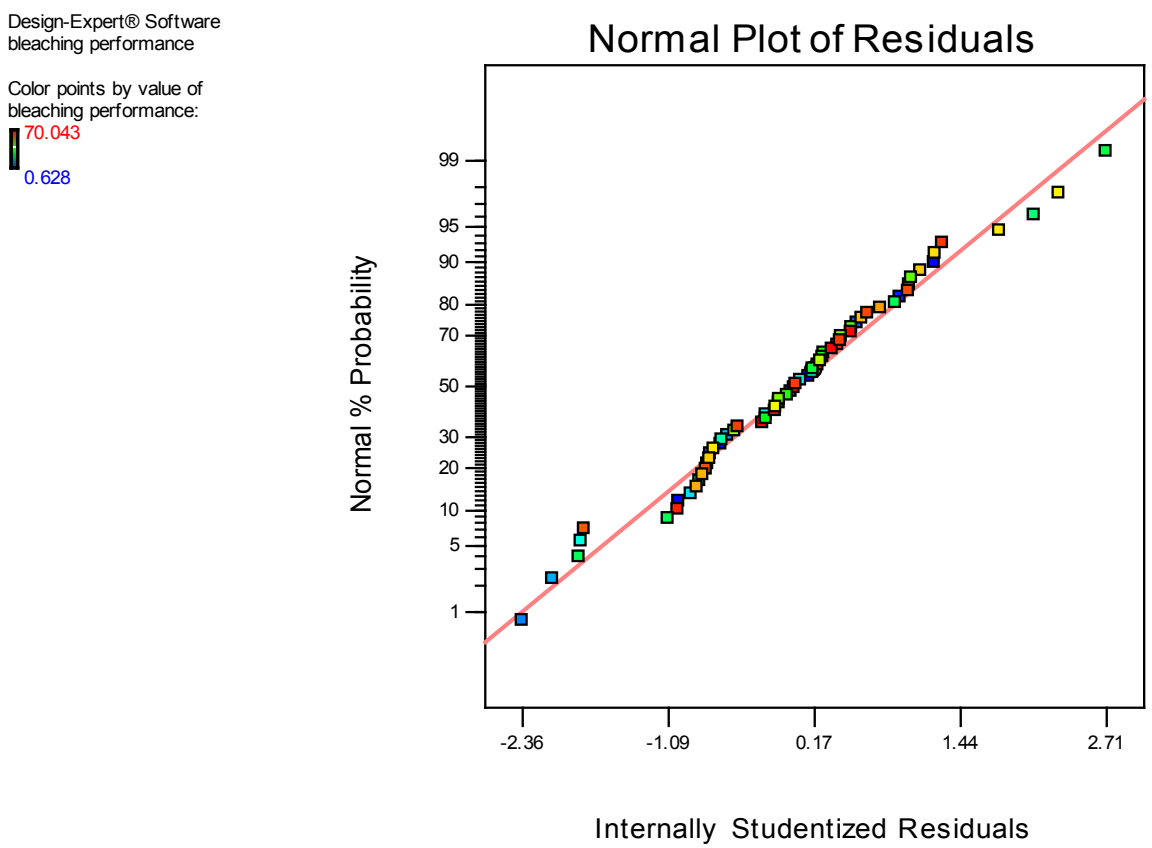

Figure 1. Normal plot of residuals.

\subsubsection{Predicted vs. Actual}

A graph of the actual response values versus the predicted response values is depicted in Figure 2. It helps to detect a value, or group of values, that are not easily predicted by the model. The data points should be spitted evenly by the 45 degree line as it is seen in the graph.

\subsection{Model Graphs}

Figure 3 shows the response surface plot for bleaching performance as a function of bleaching temperature and adsorbent dosage. The interacting effect of temperature and adsorbent dosage has a positive influence on the crude palm oil bleaching. It was observed that increasing the APPA dosage from 1.0 gram to 4.0 grams increased the bleaching efficiency. The results clearly indicate that the bleaching efficiency increases to an optimum value at adsorbent dosage of $4.0 \mathrm{~g}$, this result is in agreement with the reports of [6] [13]. It is also observed that the bleaching efficiency increases as temperature increased. An optimum value of $70 \%$ bleaching performance was attained as the temperature reached $160^{\circ} \mathrm{C}$, it was observed that further increase in temperature darkens the colour of oil.

The effect of contact time and temperature on the bleaching efficiency is depicted in Figure 4. From the plot, bleaching does not proceed to any appreciable 
Design-Expert $\circledast$ Software bleaching performance

Color points by value of bleaching performance:

70.043

0.628

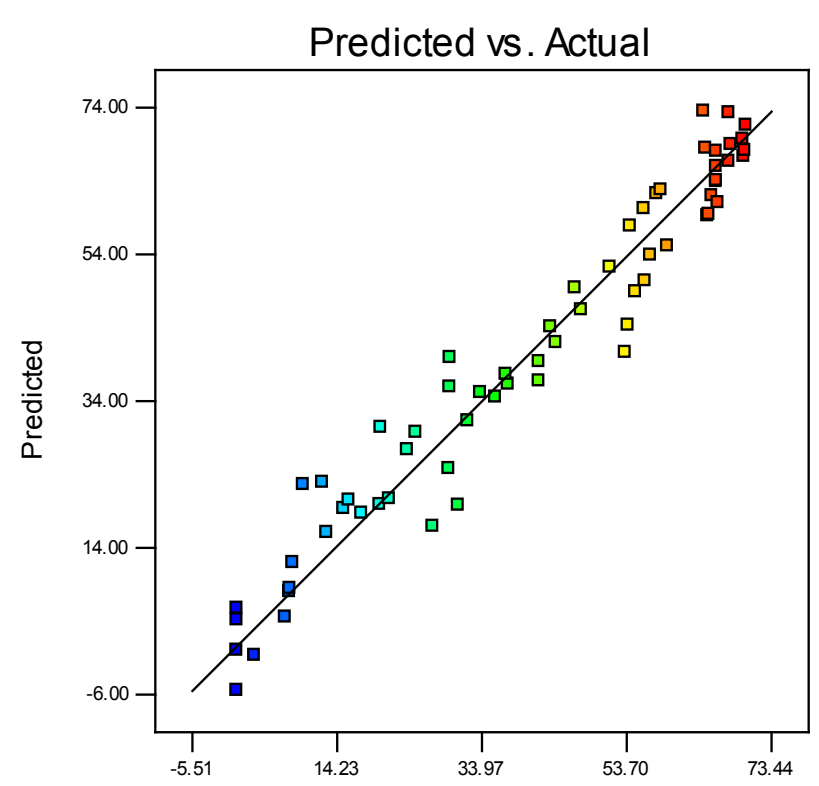

Actual

Figure 2. A plot of predicted vs. actual.

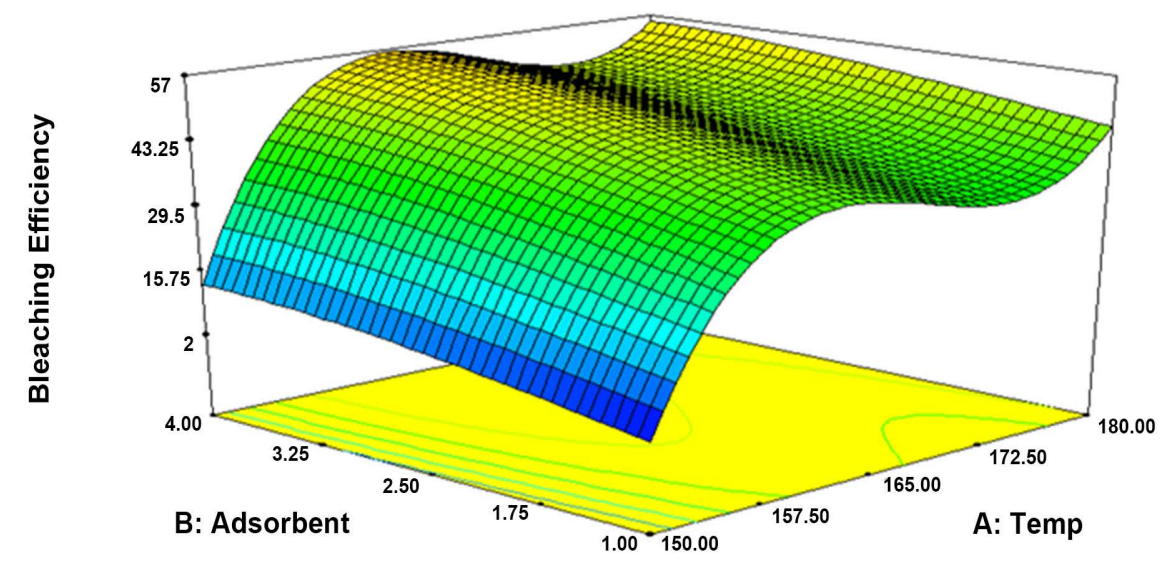

Figure 3. Effect of temperature and adsorbent dosage on the bleaching efficiency of crude palm oil.

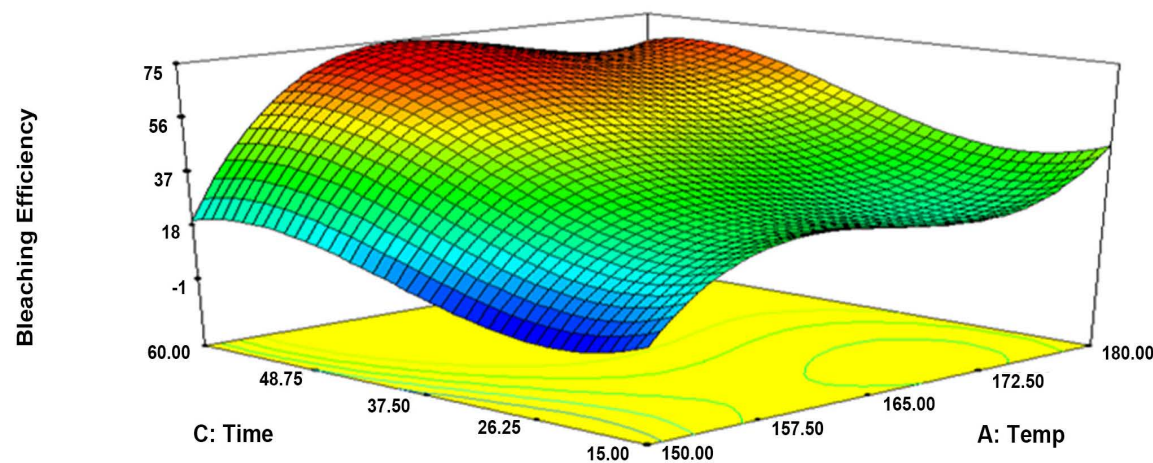

Figure 4. Effect of contact time and temperature on the bleaching performance of crude palm oil. 


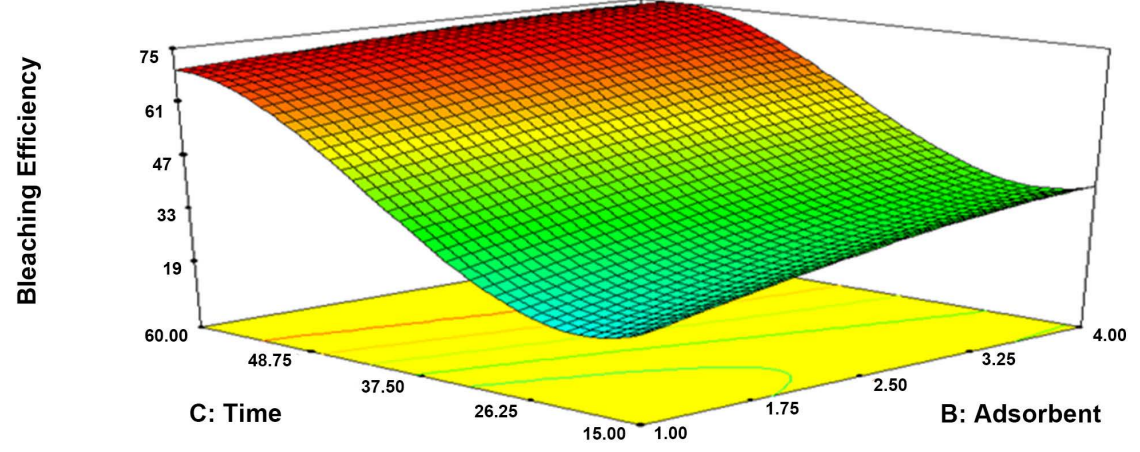

Figure 5. Effect of adsorbent dosage and contact time on the bleaching performance of crude palm oil.

degree at low contact time but as the time increased from 15 mins to 60 mins, the bleaching performance increased showing that reaction time favours and promotes access to further adsorption sites. It can be deduced that for essentially all bleaching temperatures investigated, the bleaching efficiency increases with contact time. A further increase of the temperature and time beyond $160^{\circ} \mathrm{C}$ and 60 minutes respectively may not have significant effect on the bleaching process. It is worthy to note that time and temperature factors in bleaching of palm oil improves the bleaching efficiency.

The surface response curve of the calculated response (bleaching performance) against time and adsorbent dosage at constant temperature is shown in Figure 5. The adsorbent dosage was varied from $1.00 \mathrm{~g}$ to $4.00 \mathrm{~g}$. The increase in bleaching performance of APPA on the oil was as a result of an increase in the number of active sites available for adsorption. Noticeable change in the bleaching of the crude oil was observed as the time increases from 15 minutes to 60 minutes. This is as a result of the palm oil having more interfacial contact with the adsorbent which improves the bleaching process.

\section{Conclusion}

The use of low-cost adsorbent developed from activated plantain peel ash (APPA) in adsorptive bleaching of palm oil has been investigated in this work. HDD in response surface methodology was successfully applied in the experimental design in order to optimize the process operating parameters such as time, temperature and adsorbent dosage on the bleaching efficiency. The optimum bleaching efficiency of $70 \%$ was obtained at 60 mins reaction time, $4 \mathrm{~g}$ adsorbent dosage and $160^{\circ} \mathrm{C}$ reaction temperature. Hence, the activated plantain peel ash has proved to be a good source of local adsorbent by performing optimally in the bleaching of crude palm oil.

\section{Conflicts of Interest}

The authors declare no conflicts of interest regarding the publication of this paper. 


\section{References}

[1] Chigozie, U.F. and Stone, O.R. (2014) Experimental Process Design for Sorption Capacity of Kogi And Ibusa Clay Activated with $\mathrm{HNO}_{3}$ and $\mathrm{H}_{2} \mathrm{SO}_{4}$ in Palm Oil Bleaching. Journal of Emerging Trends in Engineering and Applied Sciences (JETEAS), 5, 174-182.

[2] Usman, M.A., Ekweme, V.I., Alaye, T.O. and Mohammed, A.O. (2012) Characterization, Acid Activation and Bleaching Performance of Ibeshe Clay. ISRN Ceramics, 2012, Article ID: 658508.

[3] Nwabanne, J.T. and Ekwu, F.C. (2013) Decolourization of Palm Oil by Nigerian Local Clay, a Study of Adsorption Isotherms and Bleaching Kinetics. International Journal of Multidisciplinary Sciences and Engineering, 4, 20-27.

[4] Usman, M.A., Oribayo, O. and Adebayo, A.A. (2013) Bleaching of Palm Oil by Activated Local Bentonite and Kaolin Clay from Afashion, Edo-Nigeria. Chemical and Process Engineering Research, 10, 1-12.

[5] Mohammed, S.G., Ahmed, S.M., Badawi, A.F.M. and El-Desonki, D.S. (2015) Activated Carbon Derived from Egyptian Banana Peels for Removal of Cadmium from Water. Journal of Applied Life Science International, 3, 77-88. https://doi.org/10.9734/JALSI/2015/16652

[6] Agatemor, C. (2008) Some Aspects of Palm Oil Bleaching with Activated Plantain Peel Ash. Food Science and Technology Research, 14, 301-305. https://doi.org/10.3136/fstr.14.301

[7] Annadurai, G., Juang, R.S. and Lee, D.J. (2002) Factorial Design Analysis of Adsorption of Activated Carbon on Activated Carbon Incorporated with Calcium Aginate. Advances in Environmental Research, 6, 191-198. https://doi.org/10.1016/S1093-0191(01)00050-8

[8] Kumar, A., Prasad, B. and Mishra, I.M. (2008) Adsorptive Removal of Acrylonitrile Using Powered Activated Carbon. Journal of Environmental Protection Science, 2, 54-62.

[9] Ko, D.C.K., Porter, J.F. and McKay, G. (2000) Optimized Correlations for the Fixed Bed Adsorption of Metal Ions on Bone Char. Chemical Engineering Science, 55, 5819-5829. https://doi.org/10.1016/S0009-2509(00)00416-4

[10] Park, K. and Ahn, J.H. (2004) Design of Experiment Considering Two-Way Interactions and Its Application to Injection Molding Processes with Numerical Analysis. Journal of Materials Processing Technology, 146, 221-227. https://doi.org/10.1016/j.jmatprotec.2003.10.020

[11] Jeong, G.T., Yang, H.S. and Park, D.H. (2009) Optimization of Transesterification of Animal Fat Ester Using Response Surface Methodology. Bioresource Technology, 100, 25-30. https://doi.org/10.1016/j.biortech.2008.05.011

[12] EjikemeEbere, M., Egbuna, S.O. and Ejikeme, P.C.N. (2013) Optimal Bleaching Performance of Acid Activated Ngwulangwu Clay. International Journal of Engineering and Innovative Technology (IJEIT), 3, 13-19.

[13] Egbuna, S.O., Mbah, C.N. and Chime, T.O. (2015) Determination of the Optimal Process Conditions for the Acid Activation of Ngwo Clay in the Bleaching of Palm Oil. International Journal of Computational Engineering Research (IJCER), 5, 17-29.

[14] Larouci, M., Safa, M., Meddah, B., Aoues, A. and Sonnet P., (2015) Response Surface Modeling of Acid Activation of Raw Dialomite using Sunflower Oil Bleaching by: Box-Behnken Experimental Design. Journal of Food Science and Technology, 52, 1677-1683. https://doi.org/10.1007/s13197-013-1113-9 
[15] Chong, W.-T., Tan, C.-P., Cheah, Y.-K., Lajis, A.F.B., Habi Mat Dian, N.L., Kanagaratnam, S., et al. (2018) Optimization of Process Parameters in Preparation of Tocotrienol-Rich Red Palm Oil-Based Nanoemulsion Stabilized by Tween80-Span 80 Using Response Surface Methodology. PLoS ONE, 13, 1-22.

https://doi.org/10.1371/journal.pone.0202771 